\title{
(2S,5R)-2-Methylaminomethyl-1-methyl-5- phenylpyrrolidine, a chiral diamine ligand for copper(II)-catalysed Henry reactions with superb enantiocontrol $\uparrow$
}

Cite this: Chem. Commun., 2014, 50,6623

Received 2nd April 2014 Accepted 1st May 2014

DOI: $10.1039 / c 4 c c 02429$

www.rsc.org/chemcomm

\author{
Dagmar Scharnagel $\$$ Felix Prause $\$$ Johannes Kaldun, $\neq$ Robert G. Haase and \\ Matthias Breuning*
}

\begin{abstract}
A cis-2-aminomethyl-5-phenylpyrrolidine, which is easily available from methyl Boc-L-pyroglutamate, was found to be a highly efficient chiral ligand for $\mathrm{Cu}(\mathrm{II})$-catalysed Henry reactions. Excellent yields ( $>90 \%$ ) and superb levels of enantiocontrol $(98.5-99.6 \%$ ee) were reached with aromatic, heteroaromatic, vinylic, and aliphatic aldehydes (36 examples).
\end{abstract}

The Henry (or nitroaldol) reaction is a powerful tool for $\mathrm{C}-\mathrm{C}$ bond formation, because it permits rapid access to valuable synthetic intermediates such as 1,2-amino alcohols and $\alpha$-hydroxy acids. ${ }^{1}$ Tremendous advances have been made over the last two decades in the development of enantioselective versions of this reaction. ${ }^{2}$ Among the many highly efficient systems based on heterobimetal, ${ }^{3}$ transition metal, ${ }^{4-6}$ organo $^{7}$ and enzyme ${ }^{8}$ catalysis, chirally modified copper complexes have received particular attention due to the wide structural variability of the ligands (diamines, amino alcohols, amino imines, amino pyridines, imino pyridines, Schiff bases, box-type ligands, salen-type ligands, and others), ${ }^{5,6}$ the ease of preparation and the, in part, high levels of stereocontrol reached. Several of these catalysts permit $99 \%$ ee in the addition of nitromethane to some of the aldehydes tested, ${ }^{5}$ but none is capable of providing $99 \%$ ee for the majority of substrates. Herein we present the first copper catalyst that fulfils this demand, giving, for the addition of nitromethane to a broad range of aldehydes, the corresponding B-nitro alcohols in high yield and excellent $99 \%$ ee.

In the course of our studies on bicyclic diamines ${ }^{9}$ we became interested in 2-aminomethylpyrrolidines of general type 1 (Fig. 1), which carry an additional cis-aryl group in 5-position, as compared to proline derived diamines. Chelation of a metal with 1 will lead to a rigid bicyclic system, in which the aryl substituent is forced into an endo-position directly on top of the active metal site.

Organic Chemistry Laboratory, University of Bayreuth, Universitätsstraße 30, 95447 Bayreuth, Germany. E-mail: matthias.breuning@uni-bayreuth.de $\dagger$ Electronic supplementary information (ESI) available: Detailed experimental procedures, HPLC- and NMR spectra. See DOI: 10.1039/c4cc02429j

$\$$ These authors contributed equally to this work.

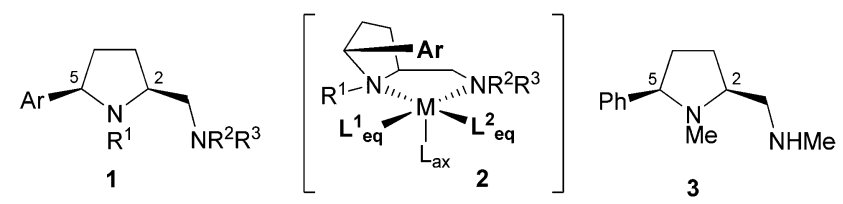

Fig. 1 cis-2-Aminomethyl-5-arylpyrrolidines 1 and $\mathbf{3}$ and a square-pyramidal metal complex of $\mathbf{1}, \mathbf{2}$.

As illustrated by complex 2, such a shielding might be of particular importance in asymmetric transition metal catalysts preferring Jahn-Teller distorted octahedral geometries, because it selectively blocks one apical position and thereby reduces the number of possible transition states. The equatorial coordination sites $\mathrm{L}_{\text {eq }}$ and $\mathrm{L}_{\text {eq }}{ }_{\text {eq }}$ are still differentiated by the intrinsic steric and electronic properties of the $C_{1}$-symmetric diamine $\mathbf{1}$, which might offer another advantage over $C_{2}$-symmetric ligands.

Copper(II)-catalysed Henry reactions, which are supposed to proceed via such a pentacoordinate intermediate, ${ }^{10}$ might provide an ideal test system to probe the potential of the diamines $1 .{ }^{11} \mathrm{After}$ investigating some derivatives, we quickly identified the simple compound 3 as the ligand of choice for these reactions. ${ }^{12}$

Diamine 3 is easily accessible from commercially available methyl Boc-L-pyroglutamate (4, Scheme 1). Treatment of 4 with phenylmagnesium chloride and re-cyclisation of the resulting, ring-opened ketone delivered the diastereomerically pure pyrrolidine 5 after crystallization. ${ }^{13}$ Exhaustive reduction followed by $\mathrm{OH} / \mathrm{NHMe}$ exchange afforded the target molecule 3 in overall seven simple steps and $40 \%$ yield.

The enantioselective Henry reactions between the aromatic aldehydes $\mathbf{6 a - u}$ and nitromethane (11 equivalents) were performed on a $1 \mathrm{mmol}$ scale in $\mathrm{THF}$ at $-25{ }^{\circ} \mathrm{C}$ (Table 1 , entries 1-21).

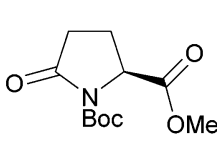

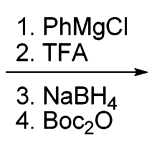

$55 \%$

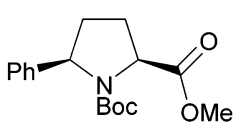

5
1. $\mathrm{LiAlH}_{4}$

$\underset{\text { 2. }}{\stackrel{\mathrm{MeNCl}}{\longrightarrow}} 3$

$72 \%$
Scheme 1 Synthesis of diamine 3 from pyroglutamate 4 . 
The copper(II) complex $\left[3 \cdot \mathrm{CuBr}_{2}\right]$, prepared prior to use by stirring $\mathrm{CuBr}_{2}$ with a slight excess of pyrrolidine 3 in THF, was used as the chiral catalyst and $\mathrm{NEt}_{3}(1.5 \mathrm{~mol} \%)$ as the base. Under these conditions $^{12}$ and in the presence of just $2 \mathrm{~mol} \%$ [3. $\mathrm{CuBr}_{2}$, the Henry products 7a-u were formed within 18 to $67 \mathrm{~h}$ in excellent 92-99\% yield. Outstanding $99 \%$ ee, in several cases even more than $99.5 \%$ ee, were obtained with electronically more or less neutral $(\mathbf{6 a}-\mathbf{g})$, electron-deficient (6h-o) and electron-rich (6p-u) aromatic aldehydes, carrying substituents in ortho-, meta-, or para-position.

Hetarylic aldehydes 8a-f were also treated with nitromethane under these conditions (Table 1, entries 22-27). And again, the Henry products $\mathbf{9 a - f}$ were obtained in excellent yields (90-99\%) and superb $>99.0 \%$ ee, irrespective of the heterocycle (furyl, thiophenyl, or NBoc-pyrryl) and the substitution pattern.

The $\alpha, \beta$-unsaturated aldehydes $10 a$ and $10 b$ solely afforded the 1,2-addition products $\mathbf{1 1 a}$ and $\mathbf{1 1 b}$. The latter one is the only compound tested within this context that delivered less than $99.0 \%$ ee, namely $98.7 \%$.

In all cases, the re-face of the aldehyde was attacked by the nitronate; the, in part, opposite absolute stereo descriptors in the products are a formal consequence of the CIP-notation.

Table 1 Aromatic, heteroaromatic and vinylic aldehyde scope ${ }^{a}$

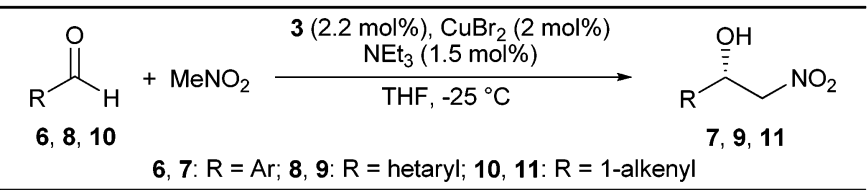

\begin{tabular}{|c|c|c|c|c|c|}
\hline Entry & Compounds & $\mathrm{R}$ & $\begin{array}{l}\text { Time } \\
\text { (h) }\end{array}$ & $\begin{array}{l}\text { Yield }^{b} \\
(\%)\end{array}$ & $\begin{array}{l}\mathrm{ee}^{c}(\%) \\
\text { (config.) }\end{array}$ \\
\hline 1 & $6 a, 7 \mathbf{a}$ & $\mathrm{Ph}$ & 24 & 92 & $99.3(S)$ \\
\hline 2 & $6 b, 7 b$ & 2-Me-Ph & 18 & 99 & $99.2(S)$ \\
\hline 3 & $6 c, 7 c$ & 3-Me-Ph & 20 & 99 & $99.5(S)$ \\
\hline 4 & $6 d, 7 d$ & 4-Me-Ph & 22 & 93 & $99.4(S)$ \\
\hline 5 & $6 e, 7 e$ & 4-Ph-Ph & 38 & 99 & $99.6(S)$ \\
\hline 6 & 6f, $7 f$ & 1-Naphthyl & 65 & 99 & $99.4(S)$ \\
\hline 7 & $6 g, 7 g$ & 2-Naphthyl & 42 & 99 & $99.0(S)$ \\
\hline 8 & $6 h, 7 h$ & $2-\mathrm{O}_{2} \mathrm{~N}-\mathrm{Ph}$ & 20 & 97 & $99.0(S)$ \\
\hline 9 & $6 \mathbf{i}, 7 \mathbf{i}$ & $3-\mathrm{O}_{2} \mathrm{~N}-\mathrm{Ph}$ & 22 & 95 & $99.4(S)$ \\
\hline 10 & $6 j, 7 j$ & $4-\mathrm{O}_{2} \mathrm{~N}-\mathrm{Ph}$ & 21 & 94 & $99.4(S)$ \\
\hline 11 & $6 \mathbf{k}, 7 \mathbf{k}$ & 2-Cl-Ph & 18 & 99 & $99.6(S)$ \\
\hline 12 & 61, 71 & 3-Cl-Ph & 19 & 96 & $99.5(S)$ \\
\hline 13 & $6 \mathrm{~m}, 7 \mathrm{~m}$ & 4-Cl-Ph & 42 & 95 & $99.5(S)$ \\
\hline 14 & $6 n, 7 n$ & $4-\mathrm{F}-\mathrm{Ph}$ & 20 & 99 & $99.6(S)$ \\
\hline 15 & 60,70 & 4-NC-Ph & 21 & 94 & $99.6(S)$ \\
\hline 16 & $6 p, 7 p$ & 2-MeO-Ph & 42 & 97 & $99.5(S)$ \\
\hline 17 & $6 q, 7 q$ & 3-MeO-Ph & 48 & 99 & $99.3(S)$ \\
\hline 18 & $6 r, 7 r$ & 4-MeO-Ph & 67 & 99 & $99.2(S)$ \\
\hline 19 & $6 s, 7 s$ & $2,4-(\mathrm{MeO})_{2}-\mathrm{Ph}$ & 48 & 98 & $99.3(S)$ \\
\hline 20 & $6 t, 7 t$ & $2,5-(\mathrm{MeO})_{2}-\mathrm{Ph}$ & 39 & 99 & $99.6(S)$ \\
\hline 21 & $6 \mathbf{u}, 7 \mathbf{u}$ & $3,4-(\mathrm{MeO})_{2}-\mathrm{Ph}$ & 40 & 93 & $99.1(S)$ \\
\hline 22 & $8 a, 9 a$ & 2-Furyl & 40 & 91 & $99.6(R)$ \\
\hline 23 & $8 b, 9 b$ & 5-Me-2-furyl & 112 & 96 & $99.5(R)^{d}$ \\
\hline 24 & $8 c, 9 c$ & 3-Furyl & 72 & 99 & $99.4(S)$ \\
\hline 25 & $8 d, 9 d$ & 2-Thiophenyl & 86 & 95 & $99.2(R)$ \\
\hline 26 & $8 e, 9 e$ & NBoc-2-pyrryl & 21 & 99 & $99.5(R)$ \\
\hline 27 & 8f, 9f & NBoc-3-indolyl & 160 & 90 & $99.4(S)$ \\
\hline 28 & $10 a, 11 a$ & $(E)-\mathrm{PhCH}=\mathrm{CH}$ & 120 & 90 & $99.3(S)$ \\
\hline 29 & $10 b, 11 b$ & (E)-1-Penten-1-yl & 90 & 97 & $98.7(S)^{d}$ \\
\hline
\end{tabular}

${ }^{a}$ Performed on a $1 \mathrm{mmol}$ scale in THF $(600 \mu \mathrm{L})$ and $\mathrm{MeNO}_{2}(600 \mu \mathrm{L} \approx$ 11 eq.). ${ }^{b}$ Isolated yield. ${ }^{c}$ Determined by HPLC analysis on a chiral phase; absolute configurations were established by comparison with literature data. ${ }^{d}$ Absolute configuration was assigned based on a $r e$-face attack on the aldehyde.
Aliphatic aldehydes 12 provided significantly lower enantioselectivities and yields under these conditions. Nonanal (12b), for example, delivered the Henry product 13b in unsatisfying $53 \%$ yield and $94.5 \%$ ee after $40 \mathrm{~h}$. In order to compensate the lower reactivity, we raised the amount of catalyst to $8 \mathrm{~mol} \%$ and the temperature to $-20{ }^{\circ} \mathrm{C}$, which afforded $\mathbf{1 3 b}$ in good $86 \%$ yield, but low $92.1 \%$ ee. Finally, a significant increase in the level of chirality transfer was observed by changing the copper salt from $\mathrm{CuBr}_{2}$ to $\mathrm{CuCl}_{2}{ }^{14}$ Under these modified conditions, both, linear (12a-c) and $\alpha$-branched (12d-g) aliphatic aldehydes provided the Henry products 13a-g in excellent $98.5-99.5 \%$ ee and $>95 \%$ yield (Table 2 ).

The stereochemical outcome of the Henry reactions can be explained via the transition state 14 (Fig. 2). As mentioned earlier, the aryl group of the chiral ligand $\mathbf{3}$ blocks the upper apical position at the $\mathrm{Cu}(\mathrm{II})$ ion, thus leaving three open coordination sites, two equatorial ones and one apical one. Based on the known model, ${ }^{10}$ the nitronate should bind apically for maximum activation, since its negative charge is less stabilised in this position by the copper ion. Of the two higher Lewis-acidic equatorial sites, the aldehyde should coordinate to the one next to the pyrrolidine moiety for two reasons: (i) this allows the sterically more demanding counter ion $\mathrm{X}$ to occupy the less congested position next to the aminomethyl group ${ }^{9 b}$ and (ii) with the weaker electron donating secondary amine opposite, the electrophilicity of the carbonyl group is increased thus facilitating a nucleophilic attack. Furthermore, the aldehyde must be oriented inwards in order to avoid severe steric repulsions with the chiral backbone. The $\mathrm{C}-\mathrm{C}$ bond formation will presumably proceed via a six-membered,

Table 2 Aliphatic aldehyde scope ${ }^{a}$

\begin{tabular}{|c|c|c|c|c|c|}
\hline \multicolumn{2}{|c|}{ 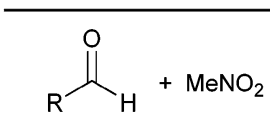 } & \multicolumn{3}{|c|}{$\begin{array}{c}3\left(8.8 \mathrm{~mol}^{2}\right), \mathrm{CuCl}_{2}(8 \mathrm{~mol} \%) \\
\mathrm{NEt}_{3}(6 \mathrm{~mol} \%)\end{array}$} & $13(\mathrm{R}=$ alkyl $)$ \\
\hline Entry & Compounds & $\mathrm{R}$ & $\begin{array}{l}\text { Time } \\
\text { (h) }\end{array}$ & $\begin{array}{l}\text { Yield }^{b} \\
(\%)\end{array}$ & $\begin{array}{l}\mathrm{ee}^{c} \\
(\%) \text { (config.) }\end{array}$ \\
\hline 1 & $12 a, 13 a$ & $n \mathrm{Bu}$ & 40 & 95 & $98.5(S)$ \\
\hline 2 & $12 b, 13 b$ & $n$ Oct & 60 & 97 & $98.6(S)$ \\
\hline 3 & $12 c, 13 c$ & $\mathrm{PhCH}_{2} \mathrm{CH}_{2}$ & 40 & 95 & $99.5(S)$ \\
\hline 4 & $12 d, 13 d$ & $\mathrm{iPr}$ & 44 & 96 & $99.1(S)$ \\
\hline 5 & $12 \mathrm{e}, 13 \mathrm{e}$ & $c$ Pent & 44 & 99 & $98.9(S)$ \\
\hline 6 & $12 f, 13 f$ & $c$ Hex & 44 & 99 & $99.4(S)$ \\
\hline 7 & $12 \mathrm{~g}, 13 \mathrm{~g}$ & $t \mathrm{Bu}$ & 44 & 99 & $98.6(S)$ \\
\hline
\end{tabular}

${ }^{a}$ Performed on a $1 \mathrm{mmol}$ scale in THF $(600 \mu \mathrm{L})$ and $\mathrm{MeNO}_{2}(600 \mu \mathrm{L} \approx$ 11 eq.). ${ }^{b}$ Isolated yield. ${ }^{c}$ Determined by HPLC analysis on a chiral phase; absolute configurations were established by comparison with literature data.

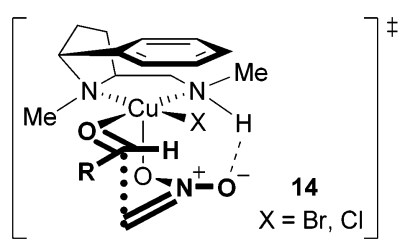

Fig. 2 Proposed transition state 14. 
chair-shaped transition state, thus obviating repulsions between the nitronate-oxygen and the pyrrolidine $N$-methyl group. ${ }^{15}$ It might be possible that this arrangement receives some further stabilisation and rigidness by an intramolecular hydrogen bridge between the nitronate oxygen and the NH-proton of the chiral ligand. Thus, the steric and electronic properties of the diamine ligand apparently create close to perfect preconditions for the experimentally observed, almost exclusive $r e$-face attack of the nitronate on the aldehyde carbonyl group.

In summary, the cis-5-phenyl substituted 2-aminomethylpyrrolidine 3, which is accessible in just a few steps from methyl Boc-L-pyroglutamate (4), was successfully utilized as the chiral ligand in $\mathrm{CuBr}_{2}$ - and $\mathrm{CuCl}_{2}$-catalysed Henry reactions. Excellent isolated yields ( $>90 \%$ ) and superb enantioselectivities (98.5-99.6\% ee) were obtained with a wide variety of aromatic, heteroaromatic, vinylic and aliphatic aldehydes (36 examples). Further studies are ongoing. ${ }^{16}$

Financial support of the German research foundation (DFG) is gratefully acknowledged.

\section{Notes and references}

1 Reviews: (a) F. A. Luzzio, Tetrahedron, 2001, 57, 915; (b) The Nitro Group in Organic Synthesis, ed. N. Ono, Wiley-VCH, New York, 2001.

2 Reviews: (a) J. Boruwa, N. Gogoi, P. P. Saikia and N. C. Barua, Tetrahedron: Asymmetry, 2006, 17, 3315; (b) C. Palomo, M. Oiarbide and A. Laso, Eur. J. Org. Chem., 2007, 2561; (c) Y. Alvarez-Casao, E. Marques-Lopez and R. P. Herrera, Symmetry, 2011, 3, 220; (d) G. Blay, V. Hernández-Olmos and J. R. Pedro, Synlett, 2011, 1195; (e) G. Chelucci, Coord. Chem. Rev., 2013, 257, 1887; $(f)$ N. Ananthi and S. Velmathi, Indian J. Chem., Sect. B, 2013, 52, 87.

3 Selected examples: (a) H. Sasai, T. Suzuki, S. Arai, T. Arai and M. Shibasaki, J. Am. Chem. Soc., 1992, 114, 4418; (b) T. Nitabaru, A. Nojiri, M. Kobayashi, N. Kumagai and M. Shibasaki, J. Am. Chem. Soc., 2009, 131, 13860; (c) T. Nitabaru, N. Kumagai and M. Shibasaki, Angew. Chem., Int. Ed., 2012, 51, 1644; (d) D. Sureshkumar, K. Hashimoto, N. Kumagai and M. Shibasaki, J. Org. Chem., 2013, 78, 11494.

4 Selected examples (except Cu-catalysis): (a) B. M. Trost and V. S. C. Yeh, Angew. Chem., Int. Ed., 2002, 41, 861; (b) C. Palomo, M. Oiarbide and A. Laso, Angew. Chem., Int. Ed., 2005, 44, 3881; (c) J. Park, K. Lang, K. A. Abboud and S. Hong, J. Am. Chem. Soc., 2008, 130, 16484; (d) S. Liu and C. Wolf, Org. Lett., 2008, 10, 1831; (e) R. Kowalczyk, P. Kwiatkowski, J. Skaržewski and J. Jurczak, J. Org. Chem., 2009, 74, 753; $(f)$ K. Lang, J. Park and S. Hong, Angew. Chem., Int. Ed., 2012, 51, 1620.

$5 \mathrm{Cu}$-catalysed Henry reactions of nitromethane giving $99 \%$ ee with at least one aldehyde: (a) M. Bandini, F. Piccinelli, S. Tommasi, A. Umani-Ronchi and C. Ventrici, Chem. Commun., 2007, 616; (b) T. Arai, M. Watanabe and A. Yanagisawa, Org. Lett., 2007, 9, 3595; (c) G. Zhang, E. Yashima and W.-D. Woggon, Adv. Synth. Catal., 2009, 351, 1255; (d) W. Jin, X. Li, Y. Huang, F. Wu and B. Wan, Chem. - Eur. J., 2010, 16, 8259; (e) G. Lai, F. Guo, Y. Zheng, Y. Fang, H. Song, K. Xu, S. Wang, Z. Zha and Z. Wang, Chem. - Eur. J., 2011, 17, 1114; $(f)$ A. T. Herrmann, S. R. Martinez and A. Zakarian, Org. Lett., 2011, 13, 3636; $(g)$ B. V. Subba Reddy and J. George, Tetrahedron: Asymmetry, 2011, 22, 1169; $(h)$ Y. Zhou, J. Dong, F. Zhang and Y. Gong, J. Org. Chem., 2011, 76, 588; $(i)$ W. Jin, X. Li and B. Wan, J. Org. Chem., 2011, 76, 484; $(j)$ R. I. Kureshy, A. Das, N. H. Khan, S. H. R. Abdi and H. C. Bajaj, ACS Catal., 2011, 1, 1529; (k) Y. Wei, L. Yao, B. Zhang, W. He and S. Zhang, Tetrahedron, 2011, 67, 8552; ( $l$ ) L. Yao, Y. Wei, P. Wang, W. He and S. Zhang, Tetrahedron, 2012, 68, 9119; $(m)$ D.-D. Qin, W.-H. Lai, D. Hu, Z. Chen, A.-A. Wu, Y.-P. Ruan, Z.-H. Zhou and H.-B. Chen, Chem. - Eur. J., 2012, 18, 10515; (n) K. Xu, G. Lai, Z. Zha, S. Pan, H. Chen and Z. Wang, Chem. - Eur. J., 2012, 18, 12357; (o) A. Das, R. I. Kureshy, K. J. Prathap, M. K. Choudhary, G. V. S. Rao, N. H. Khan, S. H. R. Abdi and H. C. Bajaj, Appl. Catal., A, 2013, 459, 97; (p) T. Deng and C. Cai, J. Fluorine Chem., 2013, 156, 183; (q) R. Ćwiek, P. Niedziejko and Z. Kałuża, J. Org. Chem., 2014, 79, 1222.

6 Selected recent examples of enantioselective Cu-catalysed Henry reactions: (a) G. Blay, V. Hernández-Olmos and J. R. Pedro, Org. Lett., 2010, 12, 3058; (b) T. Arai, Y. Taneda and Y. Endo, Chem. Commun., 2010, 46, 7936; (c) L. Cheng, J. Dong, J. You, G. Gao and J. Lan, Chem. - Eur. J., 2010, 16, 6761; (d) A. Chougnet, G. Zhang, K. Liu, D. Häussinger, A. Kägi, T. Allmendinger and W.-D. Woggon, Adv. Synth. Catal., 2011, 353, 1797; (e) M. W. Leighty, B. Shen and J. N. Johnston, J. Am. Chem. Soc., 2012, 134, 15233; $(f)$ J. D. White and S. Shaw, Org. Lett., 2012, 14, 6270; $(g)$ Q. Dai, N. K. Rana and J. C.-G. Zhao, Org. Lett., 2013, 15, 2922; (h) D.-D. Qin, W. Yu, J.-D. Zhou, Y.-C. Zhang, Y.-P. Ruan, Z.-H. Zhou and H.-B. Chen, Chem. - Eur. J., 2013, 19, 16541.

7 Selected recent examples: (a) D. Uraguchi, S. Nakamura and T. Ooi, Angew. Chem., Int. Ed., 2010, 49, 7562; (b) K. Kanagaraj, P. Suresh and K. Pitchumani, Org. Lett., 2010, 12, 4070; (c) Q. Dai, H. Huang and J. C.-G. Zhao, J. Org. Chem., 2013, 78, 4153; (d) A. Quintavalla, M. Lombardo, S. P. Sanap and C. Trombini, Adv. Synth. Catal., 2013, 355, 938; (e) S. Kitagaki, T. Ueda and C. Mukai, Chem. Commun., 2013, 49, 4030; $(f)$ M. T. Corbett and J. S. Johnson, Angew. Chem., Int. Ed., 2014, 53, 255.

8 M. Gruber-Khadjawi, T. Purkarthofer, W. Skranc and H. Griengl, Adv. Synth. Catal., 2007, 349, 1445.

9 (a) M. Breuning, D. Hein, M. Steiner, V. H. Gessner and C. Strohmann, Chem. - Eur. J., 2009, 15, 12764; (b) M. Breuning, M. Steiner, C. Mehler, A. Paasche and D. Hein, J. Org. Chem., 2009, 74, 1407; (c) M. Breuning and D. Hein, Eur. J. Org. Chem., 2013, 7575.

10 D. A. Evans, D. Seidel, M. Rueping, H. W. Lam, J. T. Shaw and C. W. Downey, J. Am. Chem. Soc., 2003, 125, 12692.

11 Enantioselective, Cu-catalysed Henry reactions using prolinederived ligands: (a) B. V. Subba Reddy, S. Madhusudana Reddy, S. Manisha and C. Madan, Tetrahedron: Asymmetry, 2011, 22, 530; (b) D. Lu, Y. Zhou, Y. Li, S. Yan and Y. Gong, J. Org. Chem., 2011, 76, 8869; (c) B. Ni and J. He, Tetrahedron Lett., 2013, 54, 462; (d) Y. Zhou, Y. Zhu, S. Yan and Y. Gong, Angew. Chem., Int. Ed., 2013, 52, 10265; (e) H. Yuan, J. Hu and Y. Gong, Tetrahedron: Asymmetry, 2013, 24, 699; $(f)$ H. A. Sema, G. Bez and S. Karmakar, Appl. Organomet. Chem., 2014, 28, 290; $(g)$ Ref. $5 e, h$ and $n$.

12 Details about the diamine screening and the optimization of the reactions conditions as well as further mechanistic investigations will be reported elsewhere.

13 Synthesis of related compounds: (a) M.-C. Fournie-Zaluski, P. Coric, V. Thery, W. Gonzalez, H. Meudal, S. Turcaud, J.-B. Michel and B. P. Roques, J. Med. Chem., 1996, 39, 2594; (b) A. Momotake, H. Togo and M. Yokoyama, J. Chem. Soc., Perkin Trans. 1, 1999, 1193; (c) A. C. Rudolph, R. Machauer and S. F. Martin, Tetrahedron Lett., 2004, 45, 4895.

14 A similar effect on the ee was not observed with aromatic aldehydes.

15 A boat-type transition state cannot fully be excluded, but seems less likely.

16 Initial studies on Henry reactions with other nitroalkanes revealed acceptable to good diastereoselectivities and excellent enantioselectivities in the major syn-diastereomer. The reaction of benzaldehyde (6a) with nitropropane, for example, afforded the corresponding B-nitro alcohol in $99 \%$ yield with a syn/anti ratio of $79: 21$ and $98 \%$ ee in the major diastereomer. 